\title{
Vida e obra do geólogo e paleontólogo John Mason Clarke
} (1857-1925)

\author{
Biography of the geologist and paleontologist John Mason \\ Clarke (1857-1925)
}

\section{Vida y obra del geólogo y paleontólogo John Mason Clarke (1857 - 1925)}

Drielli Peyerl

driellipeyerl@gmail.com

Universidade Estadual de Campinas

Elvio Pinto Bosetti

elvio.bosetti@pq.cnpq.br

Universidade Estadual de Ponta Grossa

Silvia Fernanda de Mendonça Figueirôa

figueiroa@ige.unicamp.br

Universidade Estadual de Campinas

Resumo: Em 2013, comemora-se cem anos da obra bilíngue Fósseis Devonianos do Paraná, de John Mason Clarke (1857 - 1925), publicada como a primeira monografia do Serviço Geológico e Mineralógico do Brasil, em 1913. E em homenagem a esse eminente geólogo e paleontólogo norte-americano descrevemos no presente artigo sua biografia e a contribuição de suas obras para o estudo da Paleontologia, baseando-se principalmente na obra do assistente de Clarke, Charles Schuchert, o qual em 1926 escreve a biografia de Clarke publicada pela Academia Nacional de Ciências.

Palavras-chave: John Mason Clarke. Biografia. Paleontologia.

\begin{abstract}
In 2013, it was celebrated one hundred years of the bilingual work, Fósseis Devonianos do Paraná, by John Mason Clarke (1857-1925), which was published as the first monograph of the Geological and Mineralogical Survey of Brazil in 1913. In honor of this eminent geologist and American paleontologist, it was described in this article his biography and the contribution of his work to the study of Palaeontology, based primarily on his assistant's work, Charles Schuchert, who, in 1926, wrote the biography of Clarke, published by the National Academy of Sciences.
\end{abstract}

Keywords: John Mason Clarke. Biography. Paleontology. 
Resumen: En 2013, celebramos cien años de trabajo bilingüe Fósseis Devonianos do Paraná, de John Mason Clarke (1857-1925), publicado en la primera monografía del Servicio Geológico y Mineralógico de Brasil en 1913. Y en honor a este eminente geólogo y paleontólogo estadounidense se describe en este artículo su biografía y la contribución de su trabajo al estudio de la Paleontología, basado principalmente en el trabajo de la asistente de Clarke, Charles Schuchert, quien en 1926 escribió la biografía Clarke publicado por la Academia Nacional de Ciencias.

Palabras clave: John Mason Clarke. Biografía. Paleontología.

\section{INTRODUÇÃO}

“Com a morte de John Mason Clarke, a América perde seu mais brilhante, eloquente e produtivo paleontólogo, e o mundo a maior autoridade do período e da vida devoniana."

(Charles Schuchert, 1926)

Em 1913, John Mason Clarke (1857 - 1925) publica a obra que se tornaria o referencial das descrições paleontológicas do Devoniano da Bacia do Paraná, intitulada Fósseis Devonianos do Paraná. O trabalho não apenas se refere à posição sistemática dos fósseis, mas apresenta ainda considerações sobre paleobiogeografia, paleogeografia e paleoecologia daquele patrimônio paleontológico brasileiro até então desconhecido (BOSETTI et al., 2012).

A obra bilíngue de 1913, publicada como a primeira monografia do Serviço Geológico e Mineralógico do Brasil, completa um século de existência este ano e é ainda a mais abrangente referência sobre os fósseis devonianos do sul do Brasil. Este volume comemorativo introduz uma homenagem ao eminente paleontólogo norte-americano e sua grande contribuição ao estudo da Paleontologia.

Apresenta-se, inicialmente, um resumo da vida de Clarke baseado na biografia escrita por seu assistente Charles Schuchert, em 1926, relevando-se ainda seu trabalho, suas publicações e contribuições aos estudos das ciências naturais.

\section{VIDA DE JOHN MASON CLARKE (1857 - 1925)}

John Mason Clarke nasceu em Canandaigua, Condado de Ontário, estado de Nova Iorque (Estados Unidos), no dia 15 de abril de 1857 e foi o quinto de uma família de seis filhos, crescendo na vizinhança de um dos mais espetaculares afloramentos do período Devoniano exposto na região de Finger Lakes. 
Imagem 1: Finger Lakes ${ }^{1}$.

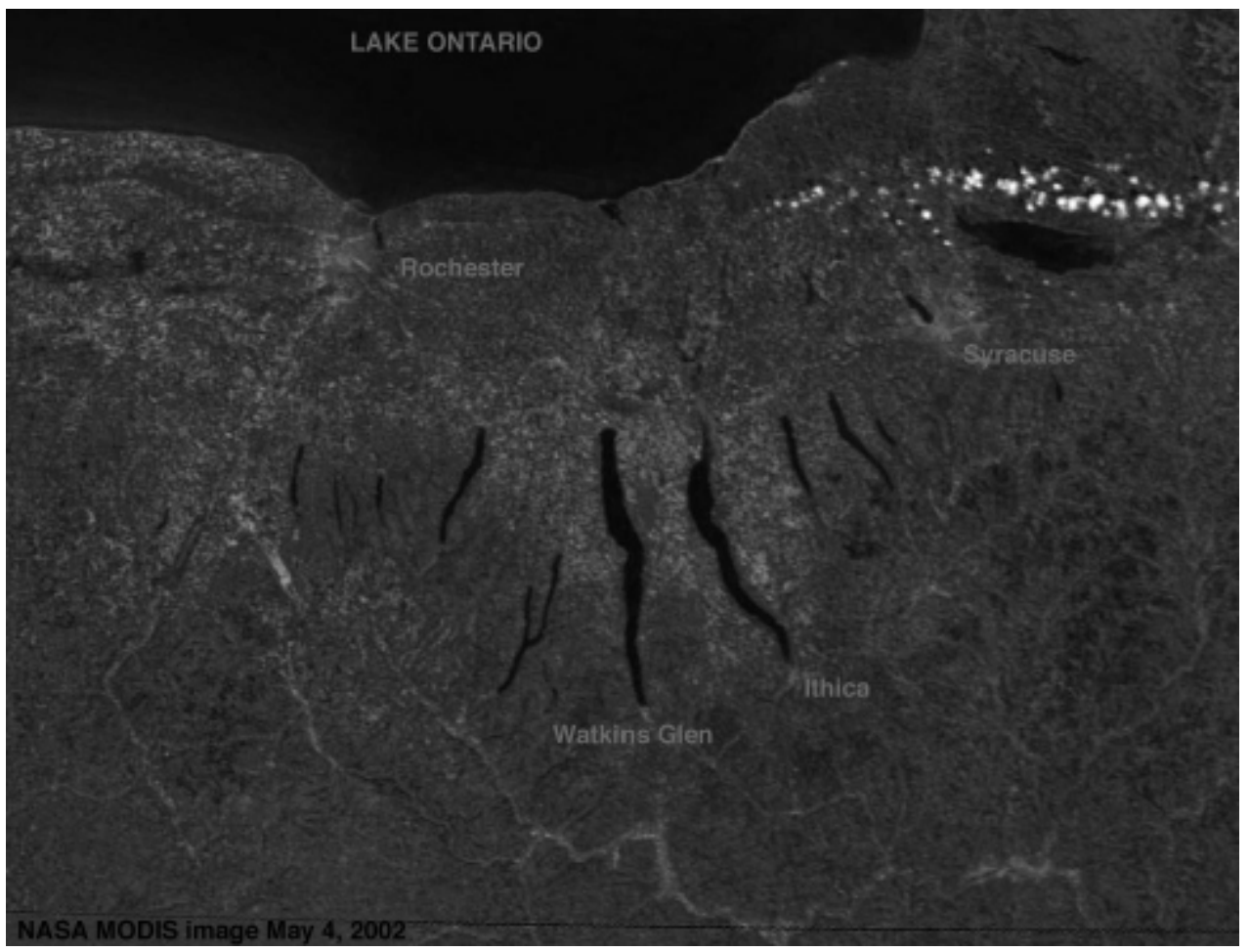

\section{REGIÃO DE FINGER LAKES'1}

Segundo Schuchert (1926), a educação obtida de seus pais e o seu local de nascimento (repleto de fósseis) foram os principais fatores que fizeram de Clarke um grande conhecedor da Geologia e da Paleontologia. Entretanto, seus mais de 450 trabalhos, entre livros e artigos, relacionavam-se à História Natural em geral, e não apenas as áreas acima mencionadas.

O seu pai, Noah Turner Clarke, por quase 50 anos foi professor de ciências, e por 30 anos diretor da Canandaigua Academy. Quando jovem, Noah Clarke acompanhou o já famoso James Hall (1811 - 1898) como guia nas ravinas e afloramentos devonianos da região de Finger Lakes. A família Clarke, portanto, teve ligações com a Geologia de Nova Iorque desde a organização e a criação do United States Geological Survey em 1879 (FIGUEIRÔA, 1997).

Em 1873, Clarke se matriculou para Amherst College (Massachusetts), onde se graduou em Geologia em 1877. No primeiro ano, Clarke teve imensas dificuldades em grego e matemática, no tocante a esta última ele mesmo se considerava 'um morto'. Entre 1879 e 1880, trabalhou como assistente de Benjamin K. Emerson em Amherst College, em seguida lecionou na Utica Free Academy (Nova Iorque) durante 1880 e 1881. 
Seguiu com o trabalho de instrutor no Smith College (Massachusetts) de 1881 a 1882. Durante seu segundo ano na Smith, seus quatro primeiros artigos científicos foram publicados e dois deles versavam sobre artrópodes do Devoniano: New phyllopod crustaceans from the Devonian of western New York e Cirriped crustacean from the Devonian. Foi neste momento que ele viajou para a Universidade de Göttingen (Alemanha), em 1883, onde iniciaria um doutorado. No entanto, uma acusação de heterodoxia pelo presidente do Smith College levou à rescisão de seus serviços. Como consequência, ele voltou para os Estados Unidos, onde retomou sua carreira de professor no Massachusetts Agricultural College entre 1884 e 1885.

Em concomitância ao trabalho de professor, Clarke continuou com o estudo do Devoniano, que ele esperava usar para sua dissertação. Os dias seguidos no retorno a Canandaigua foram utilizados para trabalhos de campo e checagem da paleofauna devoniana da região. Foi quando procurou James Hall, a quem conhecia desde 1875, e por meio de sua persistência e da influência extenuante de um senador estadual finalmente tornou-se assistente de Hall, que era então o maior paleontólogo do país.

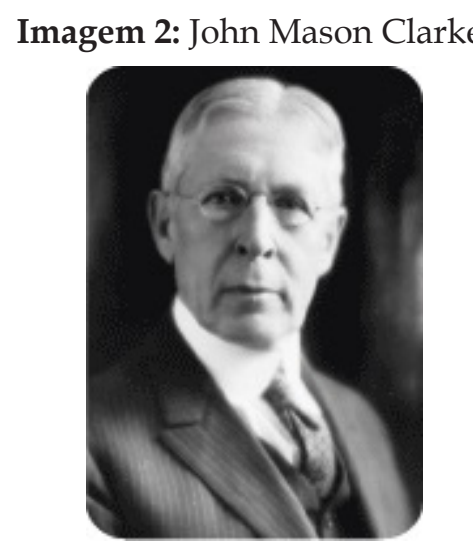

\section{JOHN MASON CLARKE (1857 - 1925) ${ }^{2}$}

Em janeiro de 1886 Clarke começa a trabalhar com James Hall no New York State Museum of Natural History, em Albany (Nova Iorque). A associação com o museu nunca foi desvinculada até o final de sua carreira.

Em 1890, Clarke descreveu o trilobita Dalmanites gonzaganus, sendo este o primeiro fóssil especificamente identificado para o Devoniano do estado do Paraná. Embora revisado mais tarde pelo próprio autor, este material pertencia à coleção enviada ao paleontólogo por Orville A. Derby (1851-1915) e Richard Rathbun (1852-1918) e é proveniente dos achados da Comissão Geológica do Império do Brasil (1875-1878). Baseado nesta coleção, Clarke publica em 1913 a obra que se tornaria o referencial das descrições paleontológicas do Devoniano da Bacia do Paraná (BOSETTI et al., 2013).

Após a morte de James Hall, em 1898, Clarke tornou-se seu sucessor como paleontólogo do Estado, e seis anos depois, em 1904, ele também se tornou geólogo e diretor do Museu do Estado de Nova Iorque em Albany, exercendo o cargo até 1925.

2 Disponível em: http://www.nysm.nysed.gov/history/html/images/faces/clarke.gif. Acesso em: 15 jul. 2013. 
Como paleontólogo e geólogo do Estado de Nova Iorque, Clarke contribuiu com seus esforços pioneiros para sustentação das pesquisas do estado e das Universidades. Ele apoiou o programa de mapeamento topográfico da United States Geological Survey (USGS) utilizando o patrocínio nesse mesmo programa para o mapeamento do Estado de Nova Iorque, o qual intensificou o levantamento das distribuições dos tipos de rochas e depósitos superficiais. Clarke, reconhecendo a importância científica de localidades regionais, assegurou doações de diversos lugares para o museu. Estes locais foram estabelecidos como 'reservas científicas' e Clarke os utilizou para o estudo com pesquisas, em exibições ao ar livre e também como propaganda para o Museu de Albany (LANDING, 2004).

Em seus 21 anos como diretor, Clarke conseguiu a expansão do Serviço Geológico, e duas das publicações mais populares do museu foram concluídas: Birds of New York (1914) e Wild Flowers of New York (1919). Palestras públicas e gratuitas anuais foram também realizadas pelo museu. Clarke também começou a adquirir terras para fins de preservação e pesquisa científica (SCHUCHERT, 1926).

Em 1916, Clarke concluiu uma grande proposta de um novo museu que seria exclusivamente dedicado ao Estado de Nova Iorque, onde atuou como diretor até sua morte em 1925. Enquanto trabalhava para o Museu do Estado, simultaneamente Clarke atuou como Professor de geologia e mineralogia do Rensselaer Polytechnic Institute, de 1894-1925.

Diferentemente de James Hall, que possuía "temperamento explosivo", Clarke ficou conhecido por sua "maneira firme e persuasiva", porém de caráter cordial, quieto e compromissado (FISHER, 1978; p.14). Clarke era fluente em quatro línguas, as quais sejam, francês, alemão, grego e inglês. Schuchert (1926) descreveu Clarke como um homem apaixonado por seu trabalho e bem relacionado com pessoas de nomes importantes do período.

Durante sua carreira, ele publicou 452 títulos, dos quais 300 são de cunho paleontológico e ou geológico. Identificou 135 novos gêneros e em torno de 870 novas espécies.

Ele foi premiado com seis graus honoríficos: Honorary Ph.D. pela University of Marburg, 1898; Honorary LL.D. pela Amherst College, 1902; Honorary Sc.D. pela Colgate University, 1909; Honorary LL.D. pela Johns Hopkins University, 1915; Honorary Sc.D. pela University of Chicago, 1916; e Honorary Sc.D. pela Princeton University, 1919.

Ele também foi nomeado o primeiro presidente da Paleontological Society em 1908, e em seguida, como vice-presidente da Geological Society of America em 1909 e seu presidente em 1916. Ainda, membro da National Academy of Sciences, e membro honorário da American Academy of Arts and Sciences, além de ser um contribuinte à American Philosophical Society e à Geological Society of London. Também recebeu ofertas de quatro universidades para presidir seus departamentos de Geologia.

Clarke faleceu no dia 29 de maio de 1925, a causa da morte foi um tumor maligno no sigmoide, que, segunto Schuchert não lhe causou sofrimento, uma vez que foi descoberto como tal somente três semanas antes de sua morte. Clarke está sepultado no 
Albany Rural Cemetery, onde também se encontram James Hall, seu ilustre antecessor e orientador, Ebenezer Emmons, RP Whitfield, e Philip Ast, todos membros do New York State Geological Survey.

Em sua biografia, são destacadas as belas palavras de John H. Finley, reitor na Universidade do Estado de Nova Iorque, posteriormente Editor do New York Times e seu amigo pessoal:

...Ele encantou-se não só com seu próprio campo da ciência, em grande parte ligado ao passado, mas também com a ciência em geral bem como ao povo do seu Estado... Ele foi o melhor amigo dos pássaros, das árvores e das flores silvestres. Ele estava mesmo preocupado com as aves migratórias que voavam em todo o Estado, e ele seguiu-as para protegê-las. E apesar de ter sido um cientista da mais alta posição, ele ainda insistia no fato de que Pã não estaria morto. "Eu o vi muitas vezes", disse ele, "entre as florestas das montanhas, eu o escutei farfalhando através dos pântanos e o vislumbrei nas sombras das piscinas de salmão ou descendo as margens de alfazema à noite." Ele não só tinha os olhos científicos para ver sob a superfície da terra, mas tinha também os ouvidos para ouvir os "tubos de juncos" que "cantam tudo o que pode ser cantado" e "dizem tudo o que pode ser dito." (SCHUCHERT, 1926; p. 184)

\section{REFERÊNCIAS}

BOSETTI, Elvio Pinto; PEYERL, Drielli; FIGUEIRÔA, Silvia Fernanda de Mendonça. Fósseis Devonianos do Paraná (1913) - Um século da obra de John Mason Clarke (1857-1925). I Simpósio Brasileiro de Paleoinvertebrados. Bauru (SP), de 10 a 14 de novembro de 2012.

FIGUEIRÔA, Silvia Fernanda de Mendonça. As Ciências Geológicas no Brasil: Uma História Social e Institucional, 1875-1934. São Paulo: Editora HUCITEC, 1997.

Finger Lakes. Disponível em: < http://www.gly.uga.edu/railsback/FieldImages/FingerLakes.jpeg >. Acesso em: 23 set. 2013.

Fisher, D.W. Laudable Legacy - A Synopsis of the Titans of Geology and Paleontology in New York State, New York State Geological Association 50th Annual Meeting Guidebook, 1978, p. 1-24.

John Mason Clarke (1857 - 1925). Disponível em: http://www.nysm.nysed.gov/history/html/images/ faces/clarke.gif. Acesso em: 15 jul. 2013.

Landing, E. 2004. Stark's Knob Scientific Reservation: recurso online disponível no New York State Museum website, http://www.nysm.nysed.gov/services/starks/index.html. Acesso em: 14 jun. 2007.

SCHUCHERT, Charles. Biographical memoir of John Mason Clarke. National Academy of Sciences, Volume XII, 1926.

Recebido em 23/10/2013

Aceito para publicação em 02/12/2013 